\title{
The ENSO phenomenon: theory and mechanisms
}

\author{
H. A. Dijkstra \\ Institute for Marine and Atmospheric Research, Dept. of Physics and Astronomy, Utrecht University, The Netherlands \\ Received: 10 August 2005 - Revised: 25 September 2005 - Accepted: 19 October 2005 - Published: 9 January 2006
}

\begin{abstract}
The El Niño variability in the equatorial Tropical Pacific is characterized by sea-surface temperature anomalies and associated changes in the atmospheric circulation. Through an enormous monitoring effort over the last decades, the relevant time scales and spatial patterns are fairly well-documented. In the meantime, a hierarchy of models has been developed to understand the physics of this phenomenon and to make predictions of future variability. In this short review, I try to summarize theories and mechanisms about El Niño variability in such a way that these are accessible to a diverse group of El Niño researchers, such as that present in Guayaquil (in May 2005) at the First International Alexander Von Humboldt Conference "The El Niño Phenomenon and its Global Impact".
\end{abstract}

\section{Introduction}

About once every four years, the sea surface temperature in the equatorial eastern Pacific is a few degrees larger than normal (Philander, 1990). Near the South American coast, this warming of the ocean water is usually at its maximum around Christmas. Long ago, Peruvian fishermen called it El Niño, the Spanish phrase for the "Christ Child". The story of the understanding of El Niño begins in India, where Sir Gilbert Walker studies the variability in the monsoon rainfall. By correlating surface pressures over the Pacific with those in India, Walker discovers a pattern which he calls the Southern Oscillation. The mean surface winds over the equatorial Pacific, the trade winds, blow from east to west and are driven by an area of average high pressure in the eastern part of the Pacific and a low pressure area over Indonesia. The Southern Oscillation consists of an irregular strengthening and weakening of the trade winds, related to the changes in surface pressure.

The mean temperature in the eastern Pacific is approximately $23^{\circ} \mathrm{C}$, with seasonal excursions of about $3^{\circ} \mathrm{C}$. During

Correspondence to: H. A. Dijkstra

(h.a.dijkstra@phys.uu.nl) the 1957-1958 El Niño, an extra warming of up to $3^{\circ} \mathrm{C}$ was observed. About a decade later, Jacob Bjerknes found that simultaneously with this El Niño, the trade winds were much weaker than normal and he discovered that both El Niño and the Southern Oscillation are part of the same phenomenon (Bjerknes, 1969). In this review, the Southern Oscillation is included when we mention El Niño, although the whole of phenomena is often referred to as ENSO (El Niño/Southern Oscillation)

After the strong 1982-1983 El Niño, it was realized that such events have an enormous impact on the weather over the globe. International monitoring programs started in the Pacific around 1985 and lead to the TAO/TRITON array. This array consists of some 70 buoys aligned on a grid over the equatorial Pacific basin having a spacing of $2^{\circ}$ in latitude, and about $15^{\circ}$ in longitude. Simultaneously, a diverse modelling effort has provided a hierarchy of models used for understanding, simulation and prediction.

In Sect. 2, ENSO is characterized from available observations, with focus on the spatial and temporal patterns involved. In Sect. 3, the coupled ocean-atmosphere processes are presented which are needed to explain the physics of the variability at the Pacific basin and interannual scales in Sect. 4. In Sect. 5, this variability is seen in a broader context to include small scale processes, usually treated as "noise" as well as the "external" processes, the latter processes controlled by factors outside the Pacific basin.

\section{Observational characterization}

During the last decade, El Niño has been observed in unprecedented detail thanks to the implementation of the TAO/TRITON array and the launch of satellite-borne instruments (McPhaden and coauthors, 1998). The relevant quantities to characterize the state in the equatorial ocean and atmosphere are sea-level pressure, sea-surface temperature, sea-level height, surface wind and ocean sub-surface temperature. 


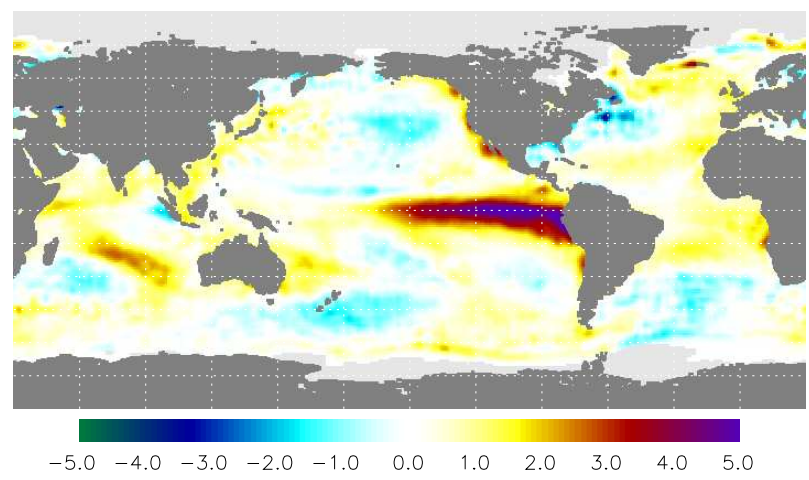

(a)

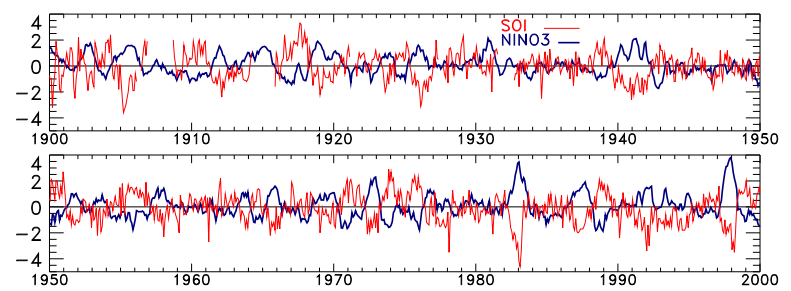

(b)

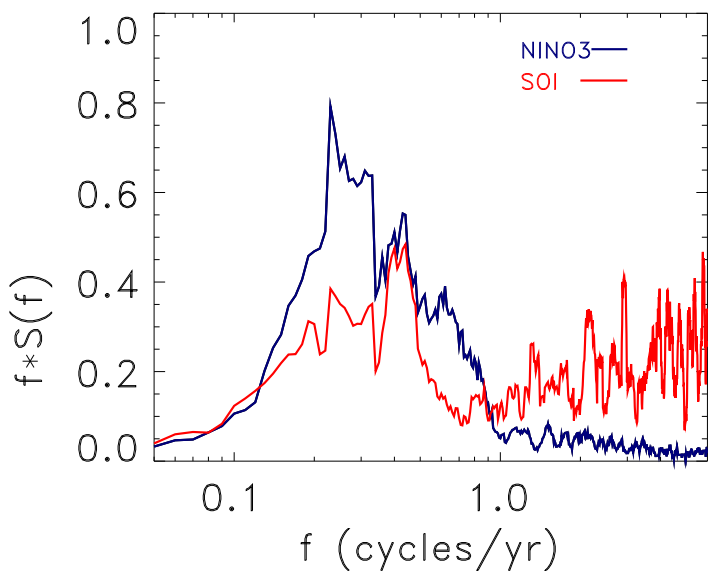

(c)

Fig. 1. (a) Sea-surface temperature anomaly field of December 1997, at the height of the 1997/1998 El Niño. Data from NCEP. (b) Monthly mean SOI and NINO3 index over the period 19001999. NINO3 is from NCEP and Kaplan et al. (1998). SOI is from NCEP and East Anglia Climate Research Unit. (c) Spectra of monthly mean SOI and NINO3. Shown are normalized periodograms smoothed over 11 bins, that is over 0.11 cycles per year. Note that $\mathrm{x}$-axis is logarithmic, and $f * S(f)$ rather than $S(f)$ is shown, in order that equal areas make equal contributions to the variance.
Monthly Zonal Wind, SST, and $20^{\circ} \mathrm{C}$ Isotherm Depth Anomalies $2^{\circ} \mathrm{S}$ to $2^{\circ} \mathrm{N}$ Average
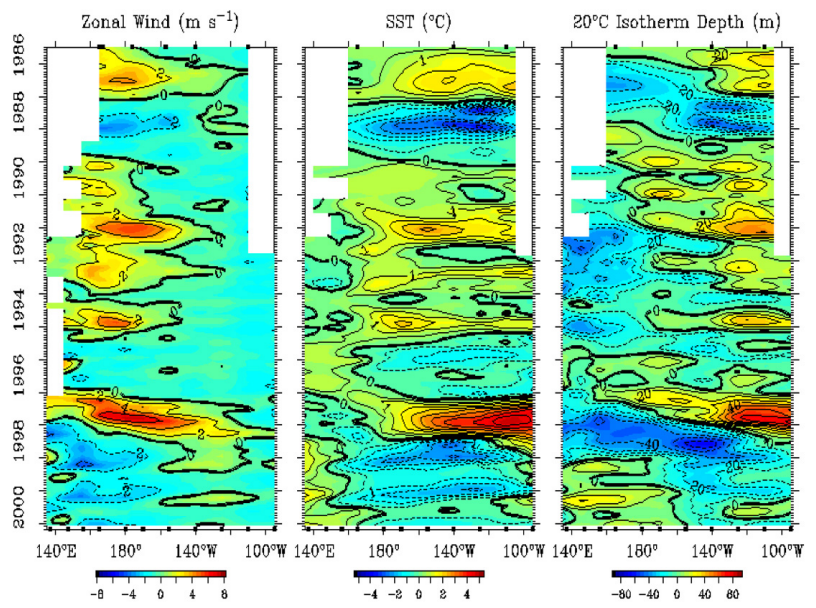

Fig. 2. (a) Time-longitude diagrams of equatorial anomalies of (a) zonal wind, (b) sea-surface temperature and (c) depth of the $20^{\circ}$ isotherm (a measure for the thermocline depth) for the period 19862000, as measured by the TAO/TRITON array. Plot made through data and software at http://www.pmel.noaa.gov/tao.

What makes El Niño unique among other interesting phenomena of natural climate variability is that it has both a well-defined pattern in space as a relatively well-defined time scale. For example, the sea-surface temperature anomaly for December 1997 (Fig. 1a) is obtained by subtracting the average over all months of December (over a long reference period) from the actual 1997 pattern. The pattern, which "springs to the eye", is characterized by higher than usual equatorial Pacific temperatures east of the date line (Rasmusson and Carpenter, 1982).

A common index of this sea-surface temperature anomaly pattern is the NINO3 index, defined as the sea-surface temperature anomaly averaged over the region $5^{\circ} \mathrm{S}-5^{\circ} \mathrm{N}$, $150^{\circ} \mathrm{W}-90^{\circ} \mathrm{W}$. In the time series (Fig. 1b), the high NINO3 periods are known as El Niño's and the low NINO3 periods as La Niña's. There is no clear-cut distinction between El Niño's, La Niña's, and normal periods, rather the system exhibits continuous fluctuations of varying strengths and durations. An index that captures the amplitude of the sea-level pressure pattern is the Southern Oscillation Index (SOI), which is the normalized difference of the pressure anomalies between Tahiti $\left(18^{\circ} \mathrm{S}, 150^{\circ} \mathrm{W}\right)$ and Darwin $\left(12^{\circ} \mathrm{S}, 131^{\circ} \mathrm{E}\right)$. The Southern Oscillation pressure pattern is associated with weaker trade winds during periods with a high NINO3 index. Generally, periods with a high NINO3 index have a low SOI and vice versa (Fig. 1b).

The SOI contains more high-frequency variability than the NINO3 index (Fig. 1c): the SOI has a white spectral tail while the NINO3 index has a red tail.

In the equatorial Pacific ocean, there is a rather sharp vertical temperature gradient, called the thermocline, that separates the surface waters from the much colder water of the bulk of the ocean. The thermocline is sometimes identified 


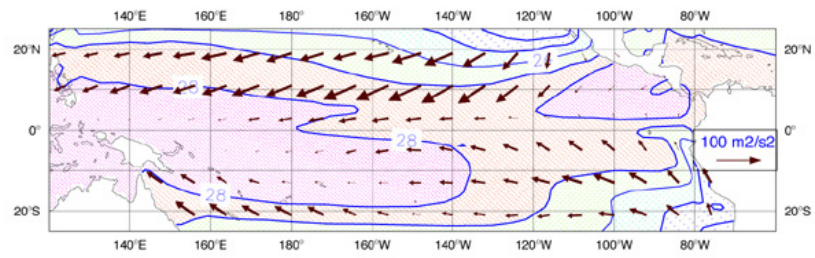

(a)

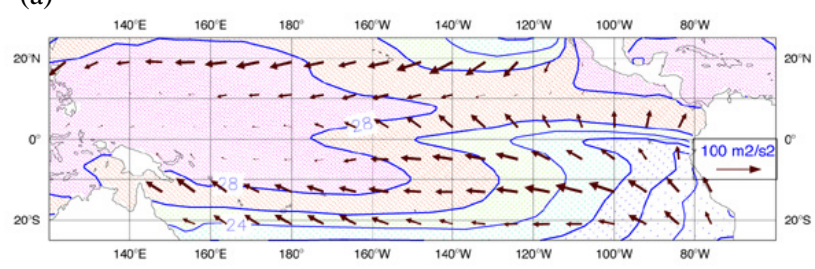

(b)

Fig. 3. Sea-surface temperature and wind stress climatologies for (a) April and (b) October. The contours give the 1961-1990 sea-surface temperature climatology (contour interval $2^{\circ} \mathrm{C}$ ) from NCEP (National Center for Environmental Prediction), the arrows the 1961-1992 pseudo wind stress climatology (in $\mathrm{m}^{2} \mathrm{~s}^{-2}$ ) from FSU (Florida State University). Pseudo wind stress has the direction of the surface wind and the magnitude of the wind speed squared.

with the $20^{\circ} \mathrm{C}$ isotherm. Anomalies in sea-level height and thermocline depth roughly vary in phase with El Niño in the eastern Pacific, and in anti-phase in the western Pacific (Fig. 2). On closer inspection, thermocline depth anomalies in the western Pacific seem to precede thermocline depth anomalies and sea-surface temperature anomalies in the eastern Pacific. Pictures with a higher temporal resolution of thermocline depth and sea-level clearly show eastward propagating waves along the equator and slower westward propagating off-equatorial waves. The wind stress variations are strongest in the western part of the basin, while the seasurface temperature variations are strongest in the eastern part (Fig. 2).

The ENSO variability is not an isolated phenomenon but takes place within the context of the Pacific (and global) climate system. An important characteristic of the equatorial Pacific climate system is its seasonal cycle and its annual mean state, together referred to as the climatology. In Fig. 3, two snapshots of the seasonal cycle of sea-surface temperature and surface winds are plotted. At the surface, northeast and southeast trade winds from the subtropics meet at the convergence zones in the equatorial regions where air rises. The air returns in the upper troposphere to the subtropics and descends, completing the so-called Hadley circulation. The southeast trades in the eastern part of the basin are weakest in April (Fig. 3a) and strongest in October (Fig. 3b). The trade winds blow toward the warm pool region which is a region of strong atmospheric deep convection and precipitation. Close to the tropopause, equatorial wind directions in the tropics tend to be opposite to that at sea level and there is eastward flow. In the arid eastern part of the basin there is little or no convection as air descends. The net zonal cell over the

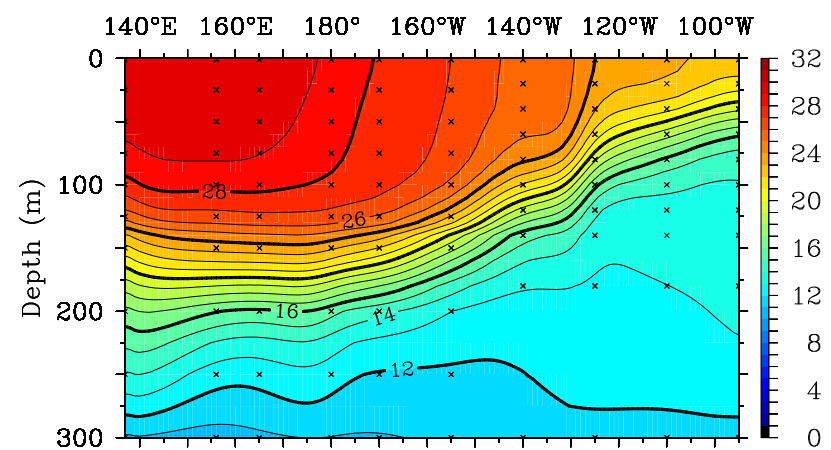

Fig. 4. Temperature $\left({ }^{\circ} \mathrm{C}\right)$ in September 2000 along the equator as a function of depth and longitude, measured by the TAO/TRITON array, showing the thermocline. Plot made through data and software at http://www.pmel.noaa.gov/tao.

equatorial Pacific is called the Walker circulation.

In April (Fig. 3a), the east-west contrast in sea-surface temperature along the equator is minimal and in October it is maximal (Fig. 3b).

The annual mean state (obtained by averaging over all months) of the equatorial Pacific sea-surface temperature is characterized by the zonal contrast between the western $\mathrm{Pa}$ cific "warm pool" and the relatively "cold tongue" in the eastern Pacific. Due to the annual mean eastward direction of the trade winds, water piles up to the Australian/Asian continent and sea level is about $50 \mathrm{~cm}$ higher in the western Pacific than in the eastern Pacific. The most striking property of the annual mean thermocline is that it slopes from a depth of about $200 \mathrm{~m}$ in the western warm pool towards a depth of about $50 \mathrm{~m}$ in the eastern cold tongue (Fig. 4). Deeper in the ocean, horizontal pressure gradients caused by the sea-level difference are compensated by the horizontal density gradients associated with the sloping thermocline.

There appear to be relations between the seasonal cycle, the spatial sea-surface temperature pattern of the annualmean state and the El Niño variability. Largest sea-surface temperature anomalies appear to occur within the cold tongue region. In addition, El Niño is to some extent phaselocked to the seasonal cycle as most El Niño's and La Niña's peak around December (Fig. 5). The root mean square of the NINO3 index is almost twice as large in December than in April.

When one considers the spectrum of the NINO3 index (Fig. 1c), also energy is found at lower frequencies, in particular in the decadal-to-interdecadal range (Jiang et al., 1995; Zhang et al., 1997; Fedorov and Philander, 2000). The strength of El Niño before the mid-1970s appears to be smaller than that after this period This is sometimes referred to as the "Pacific climate shift" (Trenberth and Hoar, 1996). According to NCEP data, the standard deviation of the SOI (NINO3) for 1951-1975 is 1.64 (0.81), to be compared for 1976-2000 where it is 1.84 (1.00). The spatial pattern of these (multi)decadal changes is fairly similar to that of the interannual variability, but the sea-surface temperature 


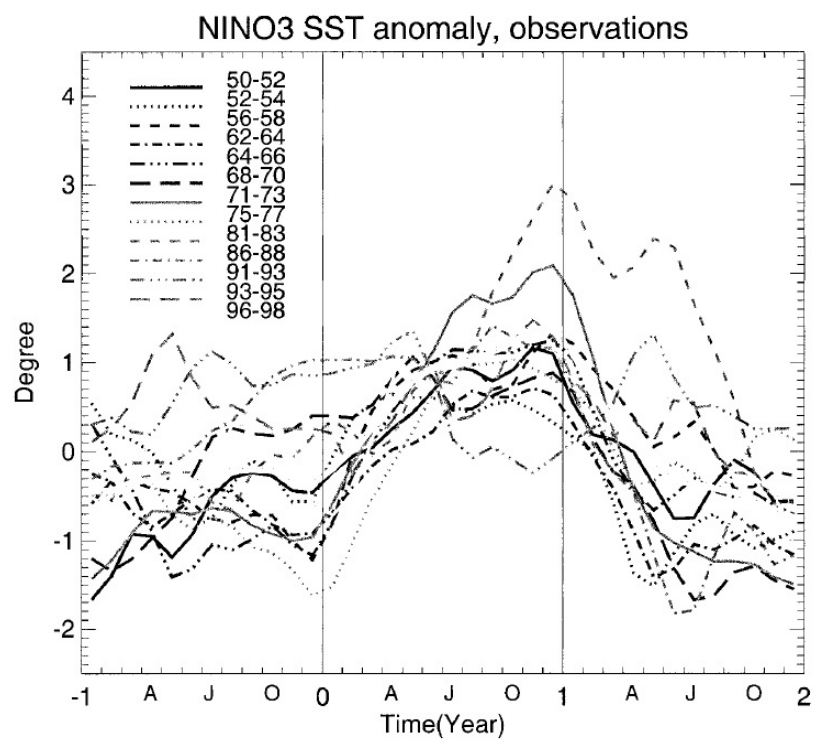

Fig. 5. NINO3 anomalies for 13 observed ENSO events from 1950 to 1998 with the mean seasonal cycle of this period removed (from Neelin et al. (2000)). The curves are aligned based on the year of the peak warm phase (at year 1).

anomalies at the eastern side of the basin extend from the equator to midlatitudes (Zhang et al., 1997).

\section{Basic processes}

The description of the climatology and variability patterns suggest that the relevant spatial scale is the whole Pacific basin and that interannual variations in sea-surface temperature, surface winds and thermocline characterize El Niño. In this section, the physical processes which control these variations are described.

\subsection{Ocean processes}

The upper ocean is generally well-mixed up to a depth of 50 $\mathrm{m}$. The temperature in this mixed layer changes due to airsea interaction, exchange processes with deeper layers and advection. Let the net heat flux from the atmosphere into the ocean and that at the bottom of the mixed layer be denoted by $Q_{o a}$ and $Q_{b}$, respectively. Under the approximation that the temperature is vertically homogeneous over the layer, one can integrate the heat balance equation over the layer which results in an equation for the mixed-layer temperature $T$ which becomes

$\frac{\partial T}{\partial t}=-\left(u \frac{\partial T}{\partial x}+v \frac{\partial T}{\partial y}\right)+F_{T}^{H}(T)+\frac{Q_{o a}-Q_{b}}{\rho C_{p} H_{m}}$

where $C_{p}$ is the heat capacity of water, $H_{m}$ the mean depth of the mixed layer, $\rho$ its mean density and $(u, v)$ are the horizontal mixed layer velocities. The quantity $F_{T}^{H}$ represents the horizontal mixing of heat through lateral turbulent exchange processes. Equation (1) states that the mixed layer

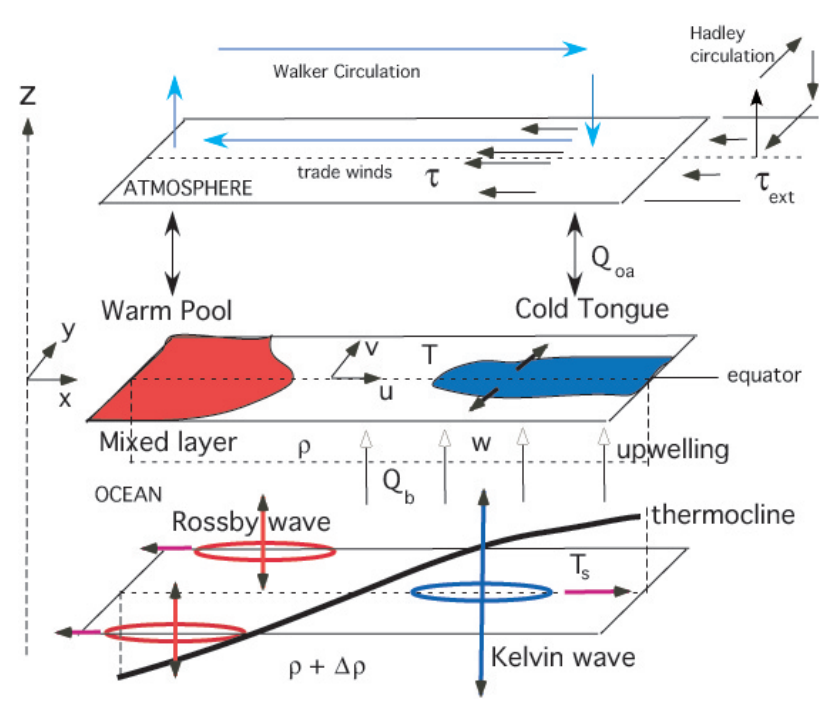

Fig. 6. Overview of the oceanic and atmospheric processes of the equatorial coupled ocean-atmosphere system.

temperature can change due to advection (first two terms in the right hand side), horizontal exchange processes and vertical exchange processes.

The net ocean-atmosphere heat flux $Q_{o a}$ can be parameterized as being proportional (Haney, 1971) to the temperature difference between the upper ocean and lower atmosphere $\left(T_{a}\right)$, i.e.,

$\frac{Q_{o a}}{\rho C_{p} H_{m}}=\epsilon_{T}\left(T-T_{a}\right)$

with $\epsilon_{T}$ being a proportionality constant. At the lower boundary of the mixed layer, an approximation of the heat flux is

$\frac{Q_{b}}{\rho C_{p} H_{m}}=w \frac{T-T_{s}}{H_{u}}$

Here, $w$ is a typical vertical velocity at the bottom of the mixed layer and $H_{u}$ is a vertical length scale such that the temperature gradient between the mixed layer and the subsurface temperature $T_{s}$ (Fig. 6) is well-approximated.

The effects of the wind stress on the upper ocean are threefold. As described above, the dominantly easterly wind stress causes water to pile up near the western part of the basin. This induces a higher pressure in the upper layer western Pacific than that in the eastern Pacific and consequently a shallowing of the thermocline towards the east. Second, the winds cause divergences and convergences of mass in the upper ocean, due to the frictional (Ekman) boundary layer in which the momentum input is transferred. North of the equator, the trade winds cause an Ekman transport to the right of the wind away from the equator. Similarly, south of the equator the Ekman mass transport is away from the equator. With a wind stress amplitude of $0.1 \mathrm{~Pa}$, a typical value of the vertical velocity is a few meters per day. Finally, the wind stress is responsible for the presence of the upper ocean currents. 
When the amplitude and/or the direction of the wind stress changes, the upper ocean adjusts through wave dynamics. The most important waves involved in this adjustment process are:

(i) Equatorial Kelvin waves. For such a wave, the meridional structure of the thermocline is maximal at the equator. Its amplitude decays exponentially in meridional direction with a decay scale $\lambda_{0}$ of about $300 \mathrm{~km}$. The zonal velocity has the same spatial structure as the thermocline and the meridional velocity is zero. The group velocity of these non-dispersive waves, say $c_{o}$, is about $2 \mathrm{~ms}^{-1}$. It takes about $\tau_{K}=3$ months to cross the Pacific basin of width $L=15000 \mathrm{~km}$.

(ii) Long equatorial Rossby waves. For such a wave, the meridional thermocline structure has an off-equatorial maximum. For each of these waves, the meridional velocity is much smaller than the zonal velocity. The group velocity of these non-dispersive waves is $c_{j}=-c_{o} /(2 j+1)$. The $j=1$ long Rossby wave travels westward with a velocity which is $1 / 3$ of that of the Kelvin wave and hence takes about $\tau_{R}=9$ months to cross the Pacific basin.

When a Kelvin wave meets the east coast, the dominant contribution of the reflected signal are long Rossby waves. Similarly, when a Rossby wave meets the west coast, it is reflected dominantly as a Kelvin wave.

The small amplitude response of the flow in an equatorial ocean basin to a certain wind field can be described as a directly forced response and a sum of free waves to satisfy the boundary conditions (Moore, 1968; Cane and Sarachik, 1977). In the response to a time-periodic wind stress, the ocean does not only react to the instantaneous wind pattern but also to previous winds through propagation of waves. Along the equator, the ocean adjustment is mainly accomplished by relatively fast eastward Kelvin waves. Off-equatorial the adjustment is accomplished by slower Rossby waves that travel westward. In such a case, the off-equatorial thermocline pattern consists partly of free Rossby waves which are adjusting to the wind and partly of a forced response which is in quasi-steady balance with the instantaneous wind stress. It is the departure of this quasisteady balance, which is crucial to further evolution of the thermocline and provides the ocean with a memory. A measure of this memory was considered in Neelin et al. (1998) to be the difference between the actual response and that which would be, at every time, in steady balance with the instantaneous wind stress. For the wind patterns over the Tropical Pacific, this "ocean memory" is largest near the western boundary.

\subsection{Coupled feedbacks}

If the underlying sea surface is warm, the air above it is heated and rises. When one assumes that convection mostly occurs over the warmest water and that the adiabatic heating

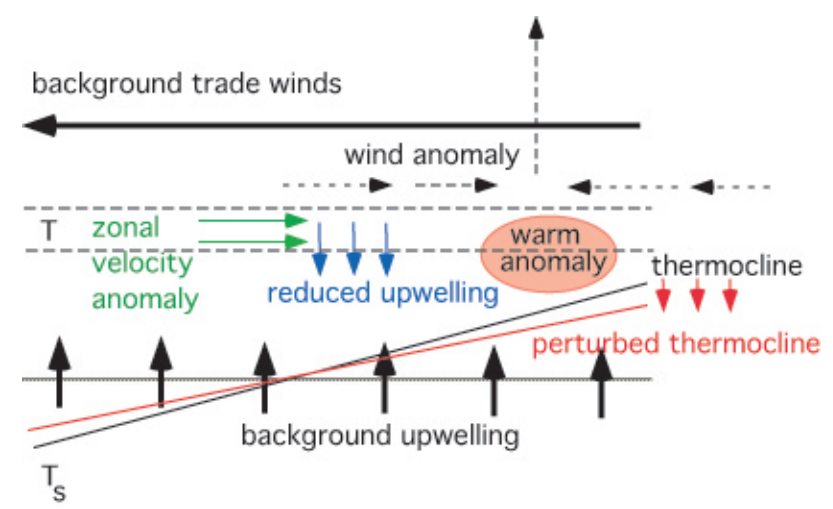

Fig. 7. Sketch to illustrate the thermocline feedback (red arrows), the upwelling feedback (blue arrows) and the zonal advection feedback (green arrows).

is dominated by heat which is released during precipitation, latent heat anomalies are proportional to sea-surface temperature anomalies, say with proportionality factor $\alpha_{T}$. In this case, a low level zonal wind response is found with westerly (easterly) winds to the west (east) of positive (negative) seasurface temperature anomalies (Fig. 7). As the zonal wind stress anomalies are proportional to the zonal wind anomalies, with proportionality factor $\gamma$, the nature of the coupling between ocean and atmosphere can now be explained. A seasurface temperature anomaly will give, through local heating, a lower-level wind anomaly. The resulting wind stress anomaly on the ocean-atmosphere surface will (i) change the thermocline slope through horizontal pressure differences in the upper ocean, (ii) change the strength of the upwelling through the Ekman divergences in the upper layer and (iii) affect the upper ocean currents $(u, v)$ in the mixed layer. The changes in velocity field and thermocline field will affect the sea surface temperature, according to (1).

The strength of the coupling between the system is determined by the combined effects of how much zonal wind anomaly is generated by sea-surface temperature anomalies and how much of the momentum of this wind is transferred as stress to the upper ocean layer. The strength of the coupling is measured by the parameter $\mu$ which is a (dimensionless) product (Dijkstra, 2000) of $\alpha_{T}$ and $\gamma$, i.e.

$\mu=\frac{\gamma \alpha_{T} \Delta T L^{2}}{c_{o}^{2} c_{a}^{2}}$

where the quantity $\Delta T$ is a typical zonal temperature difference over the basin. $L$ is the zonal length of the basin and $c_{a}=60 \mathrm{~ms}^{-1}$ is the free Kelvin wave speed in the atmosphere.

The main positive feedbacks identified in this coupled ocean-atmosphere system are referred to the thermocline, upwelling and zonal advection feedback (Neelin, 1991). They are best illustrated by looking at the growth of very small perturbations (quantities with a tilde) on a background state (quantities with a bar). Considering only the zonal advection term is Eq. (1) and neglecting quadratic terms in the per- 
turbation amplitude, the growth of temperature anomalies is described by

$$
\frac{\partial \tilde{T}}{\partial t}=-\tilde{u} \frac{\partial \bar{T}}{\partial x}-\bar{u} \frac{\partial \tilde{T}}{\partial x}
$$

with similar type of expressions for the other terms.

The thermocline feedback is best explained by looking at a sloping thermocline in a constant upwelling $(\bar{w}>0)$ ocean as sketched in Fig. 7. The sloping thermocline and the upwelling are caused by the background easterly winds. Now assume that a positive sea-surface temperature perturbation $\tilde{T}$ is present at some location, for example in the eastern part of the basin. This leads to a perturbation in the low level zonal wind which is westerly with a maximum located west of the maximum of the sea-surface temperature anomaly. Since the background winds are weakened locally, the slope of the thermocline decreases and it becomes more flat (red arrows in Fig. 7). In this case, the colder water will be closer to the surface in the west but it will be farther down in the east. Hence, the sub-surface temperature effectively increases at the level of upwelling, giving a positive heat flux perturbation at the bottom of the mixed layer. According to (1-3), i.e. $\partial \tilde{T} / \partial t \approx-\bar{w}\left(\tilde{T}-\tilde{T}_{s}\right) / H_{u}$, when $\tilde{T}_{s}-\tilde{T}>0$, the original disturbance is amplified, as $\bar{w}$ is positive. The thermocline feedback is present in a transient state, but also in an balanced (adjusted) state.

To understand the upwelling feedback, consider again a positive sea-surface temperature anomaly in the eastern part of the basin and associated changes in the wind. However, now changes in the upwelling $\tilde{w}$, mainly through the Ekman layer dynamics occur. Weaker easterly winds imply less upwelling and hence less colder water enters the mixed layer (blue arrows in Fig. 7). If $\tilde{w}<0$ and the background vertical temperature gradient is stably stratified $\left(\bar{T}>\bar{T}_{S}\right)$, then the seasurface temperature perturbation is amplified. The latter can be seen again from (1-3), i.e. $\partial \tilde{T} / \partial t \approx-\tilde{w}\left(\bar{T}-\bar{T}_{s}\right) / H_{u}$.

The zonal advection feedback arises through zonal advection of heat. Imagine a region with a strong sea surface temperature gradient, say $\partial \bar{T} / \partial x<0$. Such a region occurs for example at the east side of the warm pool. Suppose a positive anomaly in sea-surface temperature occurs leading to westerly wind anomalies. Consequently, the zonal surface ocean current $(\tilde{u}>0)$ is intensified (green arrows in Fig. 7) leading to amplification of the positive temperature perturbation, according to (1), i.e. $\partial \tilde{T} / \partial t \approx-\tilde{u} \partial \bar{T} / \partial x$. Part of the mixed layer zonal velocity will be due to wave dynamics and part due to Ekman dynamics.

\subsection{A hierarchy of coupled models}

At the moment, there is a hierarchy of coupled models available to study ENSO in the context of the global climate system. Models of Zebiak and Cane (1987) type are usually referred to as Intermediate Complexity Models (ICMs). Their ocean component usually consist of the nesting of a mixed layer and a thermocline layer (as shown in Fig. 6). A closed system of equations is obtained, once the sub-surface temperature $T_{s}$ is expressed into the thermocline deviation, say $h$, from its equilibrium value. In the first model of this kind (Zebiak and Cane, 1987), the sub-surface temperature function $T_{s}(h)$ is chosen in such a way that saturation to fixed temperatures occurs when the thermocline becomes very shallow and very deep, respectively.

Most of these models have been run in anomaly mode, which means that the model is only used to compute the anomalies with respect to a prescribed climatology, the latter being an annual mean state or a seasonal cycle. Hence, these models are aimed to study the basic physics of ENSO without any attempt to understand its context. The characteristic behavior of solutions of these models can be summarized as follows. There exists a broad parameter range where oscillatory behavior is found on interannual time scales, with recurrent warm and cold events each of about 14-18 month duration. The eastern Pacific sea surface temperature anomalies have an amplitude of about $2-3^{\circ} \mathrm{C}$. When the coupling strength $\mu$ decreases, the interannual oscillatory behavior disappears. This suggests that there is some critical threshold associated with instabilities in the coupled system related to the positive feedbacks as described in the previous subsection. The annual cycle contributes to the irregularity of the interannual oscillation. The situation in June-July appears to be most favorable for rapid growth of the sea-surface temperature anomalies and that in March-April seems less favorable.

To study ENSO within a larger context, Tropical General Circulation Models (GCMs) have been developed. Many types of models are used but essentially two different classes can be distinguished: hybrid coupled models (HCMs) and coupled general circulation models (CGCMs). Both type of models consist of a state-of-the-art ocean model, but the atmospheric components differ substantially. In CGCMs, the atmosphere is a full physical-dynamical model whereas in HCMs, it is an empirically derived (statistical) model. The advantages of an HCM are a relatively low computational cost with respect to a CGCM. In addition, there is no oversimplification of nonlinear oceanic processes as in ICMs while still the level of complexity is lower than in a CGCM allowing an easier understanding of the phenomena simulated. HCMs have been quite successful in simulating many aspects of ENSO variability (Syu and Neelin, 1995; Tang, 2002). The CGCMs can be subdivided in so-called TOGA models and global models. In TOGA models, a highresolution tropical Pacific ocean basin model is coupled to a global atmosphere model. In global CGCMs, a relatively low-resolution global ocean and atmosphere model are coupled (Delecluse et al., 1998; Latif et al., 2001).

To study aspects of the response of ICMs and GCMs in detail, simpler so-called reduced coupled models (RCMs) are used. Examples are the Jin and Neelin (1993) model, which was used to study how coupled processes lead to preferred spatial-temporal patterns, the two-strip model (Jin, 1997a), where propagation properties of preferred patterns were studied, and versions of the delayed oscillator model (Suarez and Schopf, 1988; Battisti and Hirst, 1989). In going up 
through the hierarchy of models, from RCMs through ICMs to GCMs, the degree of realism and capture of ENSO's context increases, but the level of understanding of the phenomena found decreases.

\section{Physics of El Niño variability}

Results from output of many models within this hierarchy of coupled models indicate that a preferred spatial pattern, which varies on an interannual time scale, arises spontaneously through coupled feedbacks. Spontaneous here means that infinitesimal perturbations on some background state can grow to cause finite amplitude variability (on a specific time scale) on the background state. There are two complications here: (i) the coupled processes involved in the ENSO variability also affect the background state (Sect. 4.1) and (ii) the background state is time-dependent. In Sect. 4.2, we describe how ENSO's spatial pattern and temporal behavior arise through an internal mode of variability of a particular steady background state. In Sect. 4.3, the effects of a time-dependent background state are considered.

\subsection{Coupled processes and the annual mean state}

In many early studies on ENSO variability, the annual-mean state was simply prescribed without any consideration of the processes causing this state; these states are called prescribed background states. For example, a flat thermocline can be chosen, with a spatially constant zonal temperature gradient and no-flow in both ocean and atmosphere (Hirst, 1986; Neelin, 1991). Alternatively, an annual-mean state or a seasonal cycle derived from observations can be prescribed (Zebiak and Cane, 1987).

Looking at the sea-surface temperature field of the annual mean state, it is peculiar why there is such a strong zonal asymmetry at the equator, with a warm pool in the west and a cold tongue in the east. To understand the spatial pattern of the warm pool/cold tongue, it was recognized that part of the (annual mean) wind stress in the Pacific basin is in fact related to its zonal temperature gradient (Neelin and Dijkstra, 1995). Only a small part of the wind stress, say $\boldsymbol{\tau}_{\text {ext }}$, is determined externally. The external wind stress $\boldsymbol{\tau}_{\text {ext }}$ can be taken zonally constant, imagined as being caused by the zonally symmetric atmospheric circulation.

At zero coupling strength $(\mu=0)$, the ocean circulation and consequently the sea-surface temperature is determined by the external zonal wind stress, say $\tau_{\text {ext }}^{x}$.

A small easterly wind causes a small amount of upwelling and a small slope in the thermocline. Within the model used in Van der Vaart et al. (2000), in response to this external wind with $\tau_{e x t}^{x}=-0.01 \mathrm{~Pa}$ the equatorial sea-surface temperature increases monotonically from about $25.5^{\circ} \mathrm{C}$ in the east to about $28.5^{\circ} \mathrm{C}$ in the west. The thermocline is approximately linear at the equator, its depth is increasing westwards and it has slight off-equatorial maxima near the western boundary.

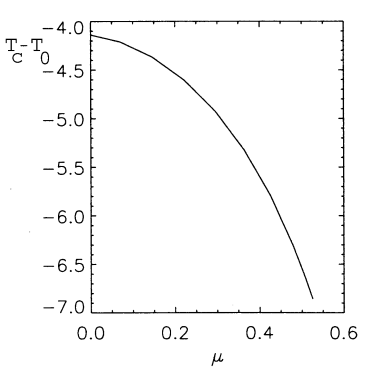

(a)

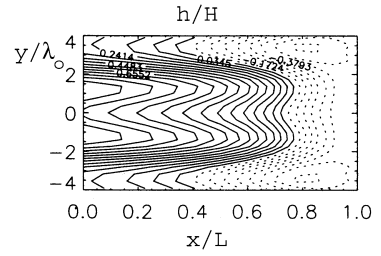

(b)
Fig. 8. (a) Eastern Pacific $(x / L=0.8)$ equatorial sea-surface temperature deviation from $T_{0}=30^{\circ} \mathrm{C}$ as a function of the coupling strength $\mu$. (b) Pattern of the thermocline depth anomaly at $\mu=0.5$. The quantities $\lambda_{0}(300 \mathrm{~km})$ and $H=100 \mathrm{~m}$ are typical meridional and vertical scales of the thermocline.

At small $\mu$, additional easterly wind stress due to coupling occurs because of the zonal temperature gradient. This leads to larger upwelling and a larger thermocline slope, strengthening the cold tongue in the eastern part of the basin. The temperature of the cold tongue $T_{C}$ is shown in Fig. 8a as a function of $\mu$. The zonal scale of the cold tongue is set by a delicate balance of the different coupled feedbacks. The thermocline field at $\mu=0.5$ (Fig. 8b) displays the off-equatorial maxima and a deeper (shallower) equatorial thermocline in the west (east). This shows that coupled processes are involved in the annual mean spatial patterns of the Pacific climate system and it also explains why the cold tongue is in the eastern part of the basin (Dijkstra and Neelin, 1995); these background states are called fullycoupled annual-mean states.

\subsection{The ENSO mode}

Taking the annual-mean state as a background state, we are now interested in its sensitivity to small perturbations. Necessary conditions for instability can be obtained by determining the linear stability boundary through normal mode analysis. In such an analysis, an arbitrary perturbation is decomposed in modes (e.g., Fourier modes) and the growth or decay of each of these modes is investigated. When the background state is stationary, the time-dependence of each mode is of the form $e^{\sigma t}$, where $\sigma=\sigma_{r}+i \sigma_{i}$ is the complex growth rate. If $\mu$ is the control parameter, then the linear stability boundary $\mu_{c}$ is the first value of $\mu$ where $\sigma_{r}=0$ for one particular normal mode. A mode with $\sigma_{i} \neq 0$ is oscillatory (with a period $2 \pi / \sigma_{i}$ ) while a mode with $\sigma_{i}=0$ is called stationary. If the growth factor of a mode is positive, sustained oscillations will occur. If the growth factor of one of these modes is negative, it will be damped. In the presence of atmospheric noise, however, the spatial pattern of such a mode can still be excited. 


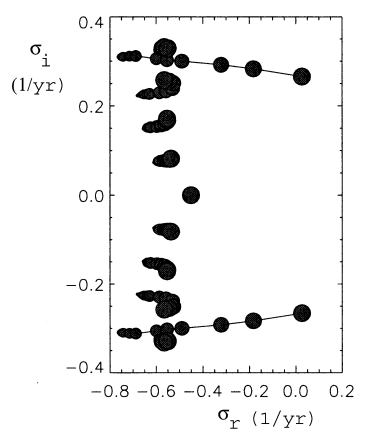

(a)
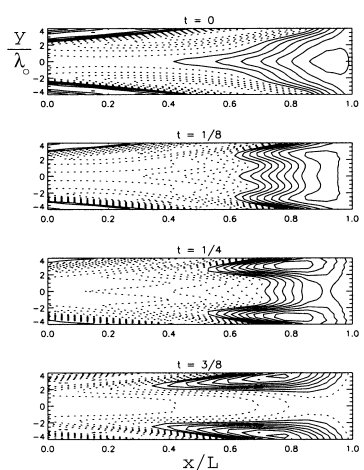

(b)
Fig. 9. (a) Plot of the eigenvalues for the six leading eigenmodes in the $(\operatorname{Re}(\sigma), \operatorname{Im}(\sigma))$-plane. Values of the coupling strength $\mu$ are represented by dot size (smallest dot is the uncoupled case $(\mu=0)$ for each mode, largest dot is the fully coupled case at the stability boundary $\left.\left(\mu_{c}=0.5\right)\right)$. (b) Planforms of the thermocline depth anomaly at several phases of the 3.7 year oscillation; time $t=1 / 2$ refers to half a period. Drawn (dotted) lines represent positive (negative) anomalies.

In early studies, the stability of a prescribed spatially constant mean state in a periodic ocean basin was considered. In this case, both uncoupled ocean and atmospheric Rossby and Kelvin waves may destabilize due to the coupled processes. The resulting unstable modes are travelling waves, which have an interannual oscillation period for wavelengths which are in the order of the basin size (Philander et al., 1984; Hirst, 1986). Also a slow westward propagating mode, a socalled SST-mode, may become unstable. This mode is not related to wave dynamics in either the atmosphere or the ocean, but to adjustment processes of SST (Neelin, 1991).

The linear stability of prescribed zonally varying annualmean states within a bounded basin was investigated in Jin and Neelin (1993). In the uncoupled case, two distinct sets of modes appear. One set is primarily related to the time scales of sea-surface temperature change (the above mentioned SST-modes) and the other set is related to time scales of ocean adjustment (ocean-dynamics modes). Depending on the other parameters in the model, the mean state can become unstable to stationary instabilities as well as oscillatory ones. In the parameter regime considered "most realistic", referred to as the "standing oscillatory" regime, merging of an oscillatory ocean dynamics mode with a stationary SST-mode occurs. This leads to slightly growing (so-called mixed SST/ocean-dynamics) modes, which inherit their spatial structure from the stationary SST-mode, but for which their interannual oscillation period is set by ocean subsurface dynamics (Neelin et al., 1994).

The linear stability of the fully coupled annual-mean states in Fig. 8 was studied in Van der Vaart et al. (2000). In Fig. 9a, the path of six modes - which become leading eigenmodes at high coupling - is plotted as a function of the coupling strength $\mu$. A larger dot size indicates a larger value of $\mu$ and both oscillation period and growth rate of the modes are given in year ${ }^{-1}$. The growth rate of one oscillatory mode becomes positive as $\mu$ is increased beyond $\mu=0.5$. The equatorial sea-surface temperature pattern of this mode displays a nearly standing oscillation for which the spatial scale is confined to the cold tongue of the mean state. The wind response is much broader zonally and is in phase with the seasurface temperature anomaly. In the spatial structure of the thermocline field (plotted in Fig. 9b at several phases of the oscillation) the eastward propagation of equatorial anomalies, their reflection at the eastern boundary and subsequent off-equatorial westward propagation can be distinguished.

Using prescribed annual-mean states, Fedorov and Philander (2000) provide an overview of the dependence of the growth factor (Fig. 10a) and period (Fig. 10b) of the ENSO mode on the background conditions. The dashed curve in Fig. 10 represent zero growth (so-called neutral conditions) of the ENSO mode. Present-day estimates for the Pacific background state correspond to the area near the points $A$ and $B$, with a period of 2-6 years and near neutral conditions.

In each of the models above, oscillatory El Niño behavior is found slightly above critical conditions followed by irregular behavior at stronger coupling. Attempts have been made to derive conceptual models to explain the physics of the oscillation period and the transition to irregularity. Most of these share the ideas that one of the positive feedbacks (as discussed in Sect. 3) acts to amplify sea-surface temperature anomalies and that adjustment processes in the ocean eventually cause a delayed negative feedback. These common elements are grouped together in the delayed oscillator mechanism or "sub-surface memory paradigm". The differences between the views are subtle (Jin, 1997b) and are related to the role of the boundary wave reflections, the importance of the adjustment processes of sea-surface temperature, the dominant feedback which is responsible for amplification of anomalies and the view of the dynamical adjustment processes in the ocean. There are four type of ENSO "oscillators", the (i) "classical" delayed oscillator, (ii) the recharge/discharge oscillator, (iii) the western Pacific oscillator and (iv) the advective/reflective oscillator. Below, we only describe (i) and (ii); the other two oscillators are described extensively in Wang and Picaut (2004).

In the "classical" delayed oscillator view, the eastern boundary reflection is unimportant, the thermocline feedback is dominant and individual Kelvin and Rossby waves control ocean adjustment. A minimal model (Suarez and Schopf, 1988; Battisti and Hirst, 1989; Münnich et al., 1991) representing this behavior is a differential delay equation of the form

$$
\frac{d T(t)}{d t}=a h_{e}\left(x_{c}, t-\tau_{1}\right)-b h_{o}\left(x_{c}, t-\tau_{2}\right)-c T^{3}(t)
$$

In this equation, $a, b$ and $c$ are constants, $T$ is the eastern Pacific temperature anomaly, which is influenced by midbasin (at $x=x_{c}$ ) equatorial thermocline anomalies $h_{e}$ and off-equatorial anomalies $h_{o}$. Furthermore, $\tau_{1}=\frac{\tau_{K}}{2}$ and 


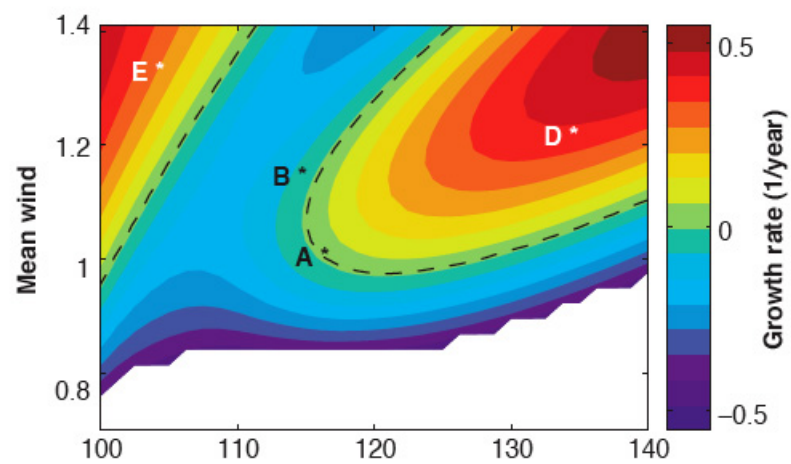

(a)

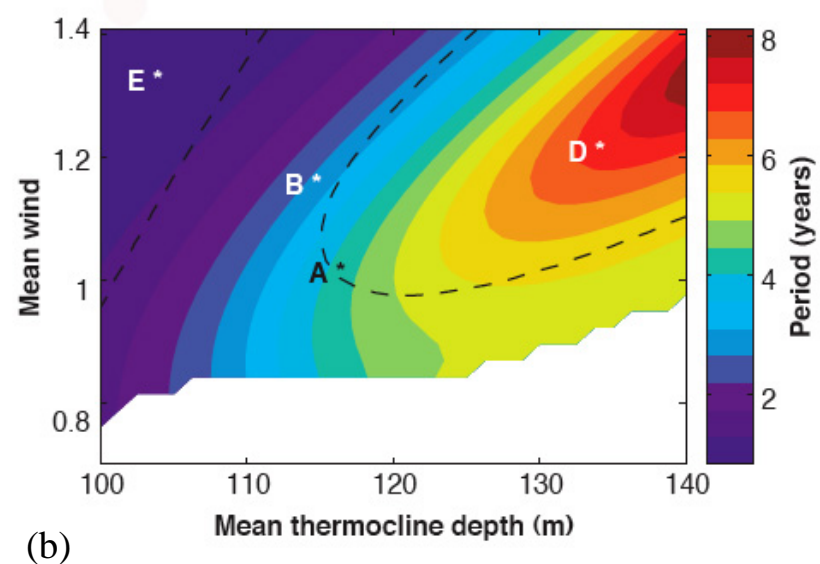

Fig. 10. Dependence of (a) growth rate $\left(\sigma_{r}\right.$ in $\left.\mathrm{yr}^{-1}\right)$ and (b) period $\left(2 \pi / \sigma_{i}\right.$ in $\left.\mathrm{yr}^{-1}\right)$ of the ENSO mode on the mean wind stress (in units of $0.5 \mathrm{~cm}^{2} \mathrm{~s}^{-2}$ ) and the mean thermocline depth (in $\mathrm{m}$ ) (Fedorov and Philander, 2000).

$\tau_{2}=\frac{\tau_{R}}{2}+\tau_{K}$ where $\tau_{K}$ and $\tau_{R}$ are the basin crossing times of the Kelvin wave and the gravest $(j=1)$ Rossby wave.

When a Kelvin wave, which deepens the thermocline, arrives in the eastern Pacific, local amplification of temperature perturbations occurs through the thermocline feedback, represented by the first term in the right hand side of (6). The wind response excites (off-equatorial) Rossby waves which travel westwards, reflect at the western boundary and return as a Kelvin wave which rises the thermocline and provides a delayed negative feedback, the second term in (6). The delay $\tau_{2}$ is the time taken for the Rossby wave to travel from the center of wind response to the western boundary plus the time it takes the reflected Kelvin wave to cross the basin. The nonlinear term is needed for equilibration to finite amplitude.

In the recharge/discharge oscillator view (Jin, 1997b), the ocean adjustment is viewed as being caused by a collective of Kelvin and Rossby waves. Adjustment of sea-surface temperature through surface layer processes is also important. Consider again a positive sea-surface temperature anomaly in the eastern part of the basin which induces a westerly wind response. Through ocean adjustment, the slope in the thermocline is changed giving a deeper eastern thermocline.

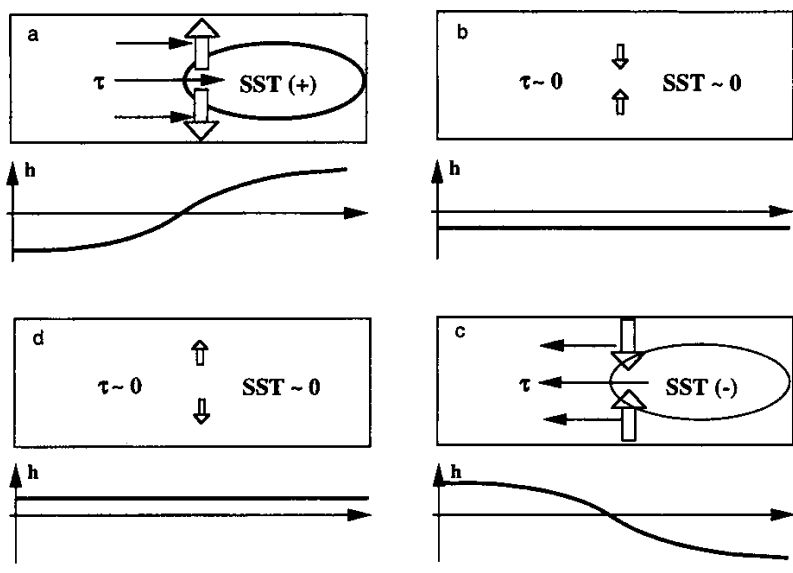

Fig. 11. Sketch of the different stages of the recharge oscillator (Jin, 1997b).

Hence, through the thermocline feedback, the sea-surface temperature anomaly is amplified which brings the oscillation to the extreme warm phase (Fig. 11a). Because of ocean adjustment, a nonzero divergence of the zonally integrated mass transport occurs and part of the equatorial heat content is moved to off-equatorial regions. This exchange causes the equatorial thermocline to flatten and reduces the eastern temperature anomaly (again the thermocline feedback plays a role) and consequently the wind stress anomaly vanishes (Fig. 11b). Eventually a non-zero negative thermocline anomaly is generated, which allows cold water to get into the surface layer by the background upwelling. This causes a negative sea-surface temperature anomaly leading through amplification to the cold phase of the cycle (Fig. 11c). Through adjustment, the equatorial heat content is recharged (again the zonally integrated mass transport is nonzero) and leads to a transition phase with a positive zonally integrated equatorial thermocline anomaly (Fig. 11d). This recharge oscillator view can be easily adapted to include the zonal advection feedback (Jin and An, 1999) as the zonal advection feedback and the thermocline feedback induce the same tendencies of sea-surface temperature anomalies.

\subsection{ENSO's phase locking to the seasonal cycle}

Fully coupled mean states with seasonal time-dependence having the correct seasonal equatorial temperature distribution are difficult to obtain within ICMs. There are strong indications that coupled processes, in particular those in the surface layer, are involved in the seasonal cycle (Philander et al., 1996). Conceptual studies have identified the equatorial north-south asymmetry as being a crucial factor in the seasonal cycle (Xie and Philander, 1994) with both evaporation and vertical mixing being able to amplify equatorial asymmetries. The stability of a seasonally varying background state has to be determined using so-called Floquet analysis and has only been applied to prescribed seasonal background states (Jin et al., 1994, 1996). It was shown that 
the spatial pattern of the ENSO mode does not change much with respect to that determined from a steady background state.

A linear mechanism for ENSO's phase locking to the seasonal cycle was proposed in Galanti and Tziperman (2000). The coupling strength $\mu(t)$ varies on a seasonal time scale and is maximal during June-July and minimal during December-January. Consider now the variation of the eastern Pacific thermocline depth $h$ in the "classical" delayed oscillator picture as described by

$$
\begin{aligned}
\frac{d h(t)}{d t} & =d \mathcal{F}\left(\mu\left(t-\tau_{1}\right) h\left(x_{c}, t-\tau_{1}\right)\right) \\
& -e \mathcal{F}\left(\mu\left(t-\tau_{2}\right) h\left(x_{c}, t-\tau_{2}\right)\right)-f h(t)
\end{aligned}
$$

Here $\mathcal{F}$ is a certain nonlinear function, the damping of thermocline anomalies is assumed to be linear (the third term in Eq. 7) and $d, e$ and $f$ are again constants. At peak time of ENSO, the eastern thermocline anomalies are maximal and hence $d h / d t \approx 0$. For small dissipation, the warming by the Kelvin wave (the first term in Eq. 7) has to balance the cooling due to the Rossby wave (the second term in Eq. 7).

Suppose that the peak of ENSO would occur during June, i.e., maximum $\mu$. In this case, the warm Kelvin wave was excited during April and because coupling is strong over April-June, it has a relatively large amplitude. The Rossby wave was, however, excited about 6 months earlier, i.e., during November-December when coupling was small. It has therefore a small amplitude and cannot balance that of the Kelvin wave $\left(\mu\left(t-\tau_{1}\right) h\left(x_{c}, t-\tau_{1}\right)\right.$ is large while $\mu\left(t-\tau_{2}\right) h\left(x_{c}, t-\tau_{2}\right)$ is small). On the other hand, when peak conditions are in December, the Kelvin wave is excited in October during relatively small coupling and its amplitude is only weakly amplified. The Rossby wave is now excited in June when coupling is large and is amplified to significant amplitude to balance the Kelvin wave thermocline signal.

\section{ENSO's complex temporal signature}

From the intermediate complexity models, a clear deterministic framework is available to explain oscillatory El Niño variability which is phase-locked to the seasonal cycle. However, these models represent only part of the physical processes at work in the Pacific ocean-atmosphere system and neglect important elements of ENSO's context. In this last section, we consider two issues where this context is essential: the mechanisms of ENSO's irregularity (Sect. 5.1) and the origin of its low-frequency variability (Sect. 5.2).

\subsection{The irregularity of El Niño}

Three different mechanisms have been suggested to explain the irregularity of ENSO, as for example seen in the NINO3 time series. These are (i) deterministic chaotic behavior, (ii) non-normal growth and (iii) impact of small-scale processes usually referred to as "noise".

Deterministic chaotic behavior can result from the interaction of the seasonal cycle and the ENSO mode (Tziperman et al., 1994; Jin et al., 1994). When the coupling strength $\mu$ is increased above criticality in ICMs which are seasonally forced, the NINO3 index displays regimes of frequency locking to the annual cycle alternated by chaotic regimes (Jin et al., 1996). In these frequency-locked regimes, the ENSO period is a rational multiple of the seasonal cycle. Although chaotic solutions are nearly everywhere in parameter space, the locked regime is also very broad. For many solutions found, the phase locking to the annual cycle is near to that observed with January being the preferred month of the peak of the warm event. It is, however, unclear from observations whether the ENSO mode has a positive or negative growth factor as indicated by Fig. 10. If the Tropical Pacific climate system is close to neutral conditions, or even stable, non-normal growth of perturbations can lead to irregular behavior (Penland and Sardeshmukh, 1995; Moore and Kleeman, 1999). In this case, certain patterns are amplified more rapidly under random initial conditions than the ENSO mode.

Under stable conditions, the effect of "noise" also can become substantial; from the perspective of El Niño, processes that evolve independently with smaller time and space scales can be considered as noise. In the atmosphere, for example, the 30-60 day or Madden-Julian oscillation (Madden and Julian, 1994) gives rise to westerly wind bursts. These are events of anomalous westerlies lasting typically a week, which are strongest somewhat west of the region of the El Niño wind response (Vecchi and Harrison, 2000). A comprehensive study of small scale oceanic variability in the equatorial Pacific is presented in Kessler et al. (1996). Kelvin waves are excited very effectively by the Madden-Julian oscillation because they travel eastward with a similar speed. Also Rossby waves are excited by individual westerly wind bursts (Van Oldenborgh, 2000). Inertia-gravity waves, which have periods up to about a week (Philander, 1990), play a role as well. The spectra of the NINO3 index and the SOI in Fig. 1c are moderately peaked compared to those of many deterministic ICMs. Hence, it is generally agreed that noise contributes substantially to the irregularity of El Niño. This is confirmed by many studies of the effect of explicit stochastic forcing in intermediate models and HCMs (e.g. Eckert and Latif (1997); Roulston and Neelin (2000)).

The picture that emerges from the available studies is that noise is the major limiting factor for the predictability of El Niño, at least for the first few seasons ahead. The growth of and sensitivity to perturbations depends on the season. The Tropical Pacific climate the system is likely to be close to neutral, with noise having a significant influence on the size of El Niño variability.

\subsection{ENSO's low-frequency variability}

With respect to the origin of (inter)decadal variability in El Niño, the proposed mechanisms can be distinguished into those that attribute a dominant role to the Tropics itself and those that involve midlatitude dynamics. 
Concerning Tropical origins, small-scale processes inevitably will lead to low-frequency variability (Kirtman and Schopf, 1998; Latif, 1998; Burgers, 1999). Flügel and Chang (1996) provide modeling evidence for stochastically induced shifts in El Niño behaviour. Another possible mechanism is that of complex nonlinear interactions between the basin scale instabilities and smaller scale processes. After all, the deterministic system may be chaotic (Mantua and Battisti, 1995; Tziperman et al., 1997) and contain a component of low frequency variability. Due to nonlinear interactions, El Niño bursting phenomena can occur (Timmermann et al., 2003), where ENSO grows to a certain amplitude, then a quick reset takes place, and small ENSO variations grow again.

Concerning mechanisms of tropical-extratropical coupling, the link between the equatorial Pacific system and the rest of the globe is both through the ocean and the atmosphere. The equatorial atmospheric circulation in the Pacific is intrinsically linked to extratropical circulation systems and the Asian monsoon system. The equatorial surface ocean current system is complicated and connects to the midlatitude circulation in the North- and South Pacific. Through transport of heat, both the thermocline shape and the subsurface temperature may be changed on time scales, which are controlled by processes other than those involved in El Niño.

In some simulations of global climate models, the dominant mechanism of low frequency variability of El Niño has its origin in the decadal variability in the extratropical atmospheric winds (Barnett et al., 1999; Pierce et al., 2000). The large scale changes influence the trade winds and precondition the mean state of the thermocline in the equatorial ocean leading to prolonged periods of enhanced or reduced El Niño variability. There is also a clear linking of the Walker circulation with other tropical circulation systems, such as that over the Atlantic and the South-Asian monsoon (Webster et al., 1996). Each year in northern Spring, the center of tropical convection migrates from the western Pacific warm pool to the northwest, announcing the arrival of the Asian monsoon. Normally, a weak Asian summer monsoon circulation is found during strong El Niño events. The normal low pressure system over the western Pacific shifts eastwards during El Niño events. Because of anomalous high pressure over the western Pacific/South Asian continent, precipitation is decreased. On the other hand, a strong monsoon with heavy rains and corresponding strong easterly winds tends to oppose El Niño conditions.

Sub-surface propagation of midlatitude ocean temperature anomalies may also lead to interdecadal variability as demonstrated in a simple model ( $\mathrm{Gu}$ and Philander, 1997). Temperature anomalies are formed in the winter mixed layer at midlatitudes, subduct when restratification occurs, propagate along the subtropical gyre towards the equator (Deser et al., 1993). Model studies, however, indicate that these anomalies may not reach the equatorial region with sufficient amplitude to affect El Niño dynamics (Hazeleger et al., 2001). Other oceanic connections have been suggested, such as (i) the signal of extratropical waves into the western equatorial Pacific (Lysne et al., 1997) and (ii) the coupling of the meridional extent of the cold tongue to the shallow meridional overturning circulation connecting the equatorial upwelling region and the North Pacific subtropical gyre (Kleeman et al., 1999).

\section{Conclusions}

Although there are still many issues which are not sufficiently well described, we can conclude that the ENSO phenomenon can be understood within a (weakly) nonlinear framework of equatorial ocean-atmosphere interaction. The oscillatory nature of ENSO derives from an internal mode of variability of the coupled system involving the coupled feedbacks and (ocean) wave dynamics. Possible mechanisms for ENSO irregularity and low-frequency variability have been suggested, but it is not clear at the moment which one is dominant.

Acknowledgements. The author thanks D. Neelin (UCLA, Los Angeles), F.-F. Jin (FSU, Tallahassee) and and P. van der Vaart (IMAU, Utrecht) for collaboration over the years.

Edited by: P. Fabian and J. L. Santos

Reviewed by: two anonymous referees

\section{References}

Barnett, T. P., Pierce, D. W., Latif, M., Dommenget, D., and Saravanan, R.: Interdecadal interactions between the tropics and midlatitudes in the Pacific basin, Geophys. Res. Lett., 26, 615-618, 1999.

Battisti, D. and Hirst, A.: Interannual variability in a tropical atmosphere-ocean model: Influence of the basic state, ocean geometry and nonlinearity., J. Atmos. Sci., 46, 1687-1712, 1989.

Bjerknes, J. P.: Atmospheric teleconnections from the equatorial Pacific, Monthly Weather Review, 97, 163-172, 1969.

Burgers, G.: The El Niño Stochastic Oscillator, Clim. Dyn., 15, 352-375, 1999.

Cane, M. A. and Sarachik, E. S.: Forced baroclinic ocean motions: II. The linear equatorial bounded case, J. Mar. Res., 35, 395-432, 1977.

Delecluse, P., Davey, M., Kitamura, Y., Philander, S. G. H., Suarez, M., and Bengtsson, L.: Coupled general circulation modeling of the tropical Pacific, J. Geophys. Res., 103, 14 357-14 374, 1998.

Deser, C., Alexander, M. A., and Timlin, C. A.: Upper-ocean thermal variations in the North Pacific during 1970-1991, J. Clim., 9, 1840-1855, 1993.

Dijkstra, H. A.: Nonlinear Physical Oceanography: A Dynamical Systems Approach to the Large Scale Ocean Circulation and El Niño., Kluwer Academic Publishers, Dordrecht, the Netherlands, 2000.

Dijkstra, H. A. and Neelin, J. D.: Coupled ocean-atmosphere models and the tropical climatology. II: Why the cold tongue is in the east, J. Clim., 8, 1343-1359, 1995.

Eckert, C. and Latif, M.: Predictability of a stochastically forced hybrid coupled model of the Tropical Pacific ocean-atmosphere system, J. Clim., 10, 1488-1504, 1997. 
Fedorov, A. and Philander, S.: Is El Niño Changing?, Science, 288, 1997-2002, 2000.

Flügel, M. and Chang, P.: Stochastically induced climate shift of El Niño-Southern Oscillation, Geophys. Res. Lett., 26, 2473-2476, 1996.

Galanti, E. and Tziperman, E.: ENSO's phase locking to the seasonal cycle in the fast-SST, fast-wave and mixed-mode regimes, J. Atmos. Sci., 57, 2936-2950, 2000.

Gu, D. and Philander, S. G. H.: Interdecadal climate fluctuations that depend on exchanges between the tropics and extratropics, Science, 275, 805-807, 1997.

Haney, R. L.: Surface thermal boundary conditions for ocean circulation models, J. Phys. Oceanogr., 4, 241-248, 1971.

Hazeleger, W., Visbeck, M., Cane, M. A., Karspeck, A., and Naik, N.: Decadal upper ocean temperature variability in the Tropical Pacific, J. Geophys. Res., 106, 8971-8988, 2001.

Hirst, A. C.: Unstable and damped equatorial modes in simple coupled ocean-atmosphere models., J. Atmos. Sci., 43, 606-630, 1986.

Jiang, N., Neelin, J. D., and Ghil, M.: Quasi-quadrennial and quasibiennial varibility in the equatorial Pacific, Clim. Dyn., 12, 101112,1995

Jin, F.-F.: An equatorial recharge paradigm for ENSO. I: Conceptual Model, J. Atmos. Sci., 54, 811-829, 1997a.

Jin, F.-F.: An equatorial recharge paradigm for ENSO. II: A stripped-down coupled model, J. Atmos. Sci., 54, 830-8847, $1997 b$.

Jin, F.-F. and An, S.-I.: Thermocline and zonal advective feedbacks within the equatorial ocean recharge oscillator model for ENSO, Geophys. Res. Lett., 26, 2989-2992, 1999.

Jin, F.-F. and Neelin, J. D.: Modes of interannual tropical oceanatmosphere interaction - a unified view. I: Numerical results., J. Atmos. Sci., 50, 3477-3503, 1993.

Jin, F.-F., Neelin, J. D., and Ghil, M.: El Niño on the devil's staircase: Annual subharmonic steps to chaos, Science, 264, 70-72, 1994.

Jin, F.-F., Neelin, J. D., and Ghil, M.: El Niño/Southern Oscillation and the annual cycle: Subharmonic frequency-locking and aperiodicity, Physica D, 98, 442-465, 1996.

Kaplan, A., Cane, M. A., Kushnir, Y., Clement, A. C., Blumenthal, M. B., and Rajagopalan, B.: Analyses of global sea surface temperature 1856-1991, J. Geophys. Res., 103, 18 567-18 589, 1998.

Kessler, W., Spillane, M., McPhaden, M., and Harrison, D.: Scales of Variability in the Equatorial Pacific inferred from the Tropical Atmosphere-Ocean Array, J. Clim., 9, 2999-3024, 1996.

Kirtman, B. and Schopf, P.: Decadal Variability in ENSO Predictability and Prediction, J. Clim., 11, 2804-2822, 1998.

Kleeman, R. P., McCreary, J. P., and Klinger, B.: A mechanism for generating ENSO decadal variability, Geophys. Res. Lett., 26, 1743-1746, 1999.

Latif, M.: Dynamics of interdecadal variability in coupled oceanatmosphere models, J. Clim., 11, 602-624, 1998.

Latif, M., Sperber, K., and coauthors: ENSIP: the El Nino simulation intercomparison project, Clim. Dyn., 18, 255-276, 2001.

Lysne, J., Chang, P., and Giese, B.: Impact of extratropical Pacific on equatorial variability, Geophys. Res. Lett., 24, 2589-2592, 1997.

Madden, R. and Julian, P.: Observations of the 40-50-day tropical oscillation - A review, Mon. Wea. Rev., 122, 814-835, 1994.

Mantua, N. J. and Battisti, D. S.: Aperiodic variability in the Zebiak-Cane coupled ocean-atmosphere model: air-sea interac- tion in the western equatorial Pacific, J. Clim., 8, 2897-2927, 1995.

McPhaden, M. and coauthors: The Tropical Ocean-Global Atmosphere observing system: a decade of progress, J. Geophys. Res., 103, 14 169-14 240, 1998.

Moore, A. M. and Kleeman, R.: Stochastic Forcing of ENSO by the Intraseasonal Oscillation, J. Clim., 12, 1199-1220, 1999.

Moore, D. W.: Planetary-Gravity Waves in an Equatorial Ocean, Harvard University, Cambridge, MA, USA, 1968.

Münnich, M. M., Cane, M., and Zebiak, S. E.: A study of selfexcited oscillations of the tropical ocean-atmosphere system. II: Nonlinear cases, J. Atmos. Sci., 48, 1238-1248, 1991.

Neelin, J. D.: The slow sea surface temperature mode and the fastwave limit: Analytic theory for tropical interannual oscillations and experiments in a hybrid coupled model, J. Atmos. Sci., 48, 584-606, 1991.

Neelin, J. D. and Dijkstra, H. A.: Coupled ocean-atmosphere models and the tropical climatology. I: The dangers of fluxcorrection, J. Clim., 8, 1325-1342, 1995.

Neelin, J. D., Latif, M., and Jin, F.-F.: Dynamics of coupled oceanatmosphere models: The tropical problem, Ann. Rev. Fluid Mech., 26, 617-659, 1994.

Neelin, J. D., Battisti, D. S., Hirst, A. C., Jin, F.-F., Wakata, Y., Yamagata, T., and Zebiak, S. E.: ENSO Theory, J. Geophys. Res., 103, 14 261-14 290, 1998.

Neelin, J. D., Jin, F.-F., and Syu, H.-H.: Variations of ENSO phase locking, J. Clim., 13, 2570-2590, 2000.

Penland, C. and Sardeshmukh, P. D.: The optimal growth of tropical sea surface temperature anomalies, J. Clim., 8, 1999-2024, 1995.

Philander, S. G. H.: El Niño and the Southern Oscillation, Academic Press, New York, 1990.

Philander, S. G. H., Yamagata, T., and Pacanowski, R. C.: Unstable air-sea interactions in the tropics, J. Atmos. Sci., 41, 604-613, 1984.

Philander, S. G. H., Gu, D., Halpern, D., Lambert, G., Lau, N.-C., $\mathrm{Li}, \mathrm{T}$., and Pacanowski, R. C.: Why the ITCZ is mostly north of the equator, J. Clim., 9, 2958-2972, 1996.

Pierce, D. W., Barnett, T. P., and Latif, M.: Connections between the Pacific Ocean tropics and midlatitudes on decadal timescales, J. Clim., 13, 1173-1194, 2000.

Rasmusson, E. and Carpenter, T. H.: Variations in tropical sea surface temperature and surface wind fields associated with the Southern Oscillation/El Niño, Mon. Wea. Rev., 110, 354-384, 1982.

Roulston, M. and Neelin, J. D.: The response of an ENSO model to climate noise, weather noise and intraseasonal forcing, Geophys. Res. Lett., 27, 3723-3726, 2000.

Suarez, M. and Schopf, P. S.: A delayed action oscillator for ENSO, J. Atmos. Sci., 45, 3283-3287, 1988.

Syu, H.-H. and Neelin, J. D.: ENSO in a hybrid coupled model: Part I: Sensitivity to physical parameterizations, Clim. Dyn., 16, 19-34, 1995.

Tang, Y.: Hybrid coupled models of the tropical Pacific. I: Interannual variability, Clim. Dyn., 19, 331-342, 2002.

Timmermann, A., Jin, F.-F., and Abshagen, J.: A nonlinear theory of El Niño bursting, J. Atmos. Sci., 60, 165-176, 2003.

Trenberth, K. E. and Hoar, T. J.: The 1990-1995 El Niño Southern Oscillation event: longest on record, Geophys. Res. Lett., 23, 57-60, 1996.

Tziperman, E., Stone, L., Cane, M. A., and Jarosh, H.: El Niño chaos: overlapping of resonances between the seasonal cycle and the Pacific ocean-atmosphere oscillator, Science, 264, 72- 
74, 1994.

Tziperman, E., Zebiak, S. E., and Cane, M. A.: Mechanisms of seasonal-ENSO interaction, J. Atmos. Sci., 54, 61-71, 1997.

Van der Vaart, P. C. F., Dijkstra, H. A., and Jin, F.-F.: The Pacific Cold Tongue and the ENSO mode: Unified theory within the Zebiak-Cane model, J. Atmos. Sci., 57, 967-988, 2000.

Van Oldenborgh, G. J.: What caused the onset of the 1997/98 El Niño?, Monthly Weather Review, 128, 2601-2607, 2000.

Vecchi, G. A. and Harrison, D. E.: Tropical Pacific sea surface temperature anomalies, El Nino, and equatorial westerly wind events, J. Clim., 13, 1814-1830, 2000.

Wang, C. and Picaut, J.: Understanding ENSO Physics: A review, in: Earth's Climate: The Ocean-Atmosphere Interaction, edited by: Wang, C., Xie, S.-P., and Carton, J. A. pp. 21-48, American Geophysical Union, 2004.
Webster, P. J., Magana V. O., Palmer, T. N., Shukla, J., Tomas, R. A., Yanai, M., and Yasunari, T.: Monsoons: Processes, predictabilty, and the prospects for predicting, J. Geophys. Res., 103, 14 451-14 510, 1998.

Xie, S.-P. and Philander, S. G. H.: A coupled ocean-atmosphere model of relevance to the ITCZ in the eastern Pacific, Tellus, 46A, 340-350, 1994.

Zebiak, S. E. and Cane, M. A.: A model El Niño-Southern Oscillation., Mon. Wea. Rev., 115, 2262-2278, 1987.

Zhang, Y., Wallace, J. M., and Battisti, D. S.: ENSO-like interdecadal variability: 1900-1993, J. Clim., 10, 1004-1020, 1997. 